\title{
ESTUDO DO ESTADO DE ATIVAÇÃO DE VIAS DE SINALIZAÇÃO NO MICROABIENTE TUMORAL E LEUCÓCITOS CIRCULANTES EM PACIENTES COM TUMOR DO COLO DO ÚTERO
}

Tese apresentada ao programa de PósGraduação em Imunologia do Instituto de Ciências Biomédicas da Universidade de São Paulo, para obtenção do Título de Doutor em Ciências.

Área de concentração: Imunologia

Orientadora: Profa. Dra. Ana Paula Lepique

Versão original 


\section{RESUMO}

ROSSETTI, R. A. M. Estudo do estado de ativação de vias de sinalização no microambiente tumoral e leucócitos circulantes em pacientes com tumor do colo do útero. 2016. 125 f. Tese (Doutorado em Imunologia) - Instituto de Ciências Biomédicas, Universidade de São Paulo, São Paulo, 2016.

Segundo estimativas mundiais, o câncer do colo do útero é o quarto tipo de câncer mais frequente em mulheres, sendo o sétimo tipo mais comum na população em geral. O principal fator etiológico destes tumores é a infecção pelo Papilomavírus Humano (HPV). Os tumores associados ao HPV apresentam microambiente complexo, onde células do sistema imune reconhecem e podem montar respostas antitumorais, ao mesmo tempo em que mecanismos de evasão tumoral modulam o fenótipo das células recrutadas para o tumor, suprimindo a atividade antitumoral. As interações bioquímicas entre os diferentes elementos do microambiente tumoral são complexas e crônicas. A forma como as células presentes no microambiente tumoral integram todos os sinais gerados ao longo do tempo, reflete-se na ativação de vias de sinalização, controle de expressão gênica e finalmente na atividade das células. Por exemplo, células apresentadoras de antígenos influenciadas pelo ambiente tumoral podem apresentar redução da ativação de NFKB o que tem sido associado, em modelos experimentais, a perfil tolerogênico e falha na ativação de linfócitos $T$. $O$ objetivo deste projeto foi avaliar o estado de ativação de vias de sinalização nos compartimentos inflamatório e tumoral no local da lesão e sistemicamente, em leucócitos circulantes. Para tanto, avaliamos biópsias e células mononucleares do sangue periférico de pacientes com lesão de alto grau e câncer. Comparando lesões de alto grau (precursoras) e de câncer invasivo, nós investigamos as vias NFKB, STAT3 e Akt, e observamos que enquanto há tendência de aumento da sinalização de NFKB no microambiente tumoral, há redução significativa da ativação dessa via em leucócitos circulantes, tanto nas células apresentadoras de antígenos como nos linfócitos T. Já a via de STAT3 não apresenta variação clara de ativação entre os diferentes graus de lesão nas biópsias, mas sim aumento de atividade em leucócitos circulantes. Finalmente, a via de PI3K/Akt, apresenta aumento consistente de ativação, conforme o grau da lesão, tanto em biópsias como em células circulantes. Com a ideia de testar a hipótese de que há possibilidade de modular as respostas imunes antitumorais através da modulação de vias de sinalização, nós decidimos tratar linfócitos $B$, que podem ativar respostas secundárias de linfócitos $T$, com agonista de CD40, a fim de ativar a via de NFKB e buscar melhorar seu potencial antigênico. $O$ estímulo dos linfócitos $B$ de pacientes com lesão de alto grau e câncer com $10 \mu \mathrm{g} / \mathrm{ml}$ de sCD40L e $20 \mathrm{ng} / \mathrm{ml}$ de IL-4 por 24 horas, foi eficiente em aumentar o número de células $\mathrm{CD} 80^{+} \mathrm{CD} 6^{+}$, moléculas estas co-estimuladoras, cuja expressão é controlada por NFKB. Nossos resultados, mostram pela primeira vez um panorama do estado de ativação de vias de sinalização chave para a progressão tumoral, tanto localmente como sistemicamente, e também trazem a possibilidade de uma ferramenta imunomoduladora.

Palavras-Chaves: Câncer cervical. Papilomavírus Humano. Vias de sinalização. NFkB. STAT3. Akt. Linfócitos B. 
ABSTRACT

ROSSETTI, R. A. M. Signaling pathways characterization in tumor microenvironment and peripheral blood mononuclear cells in cervical cancer patients. 2016. 125 p. PhD Thesis (Immunology) - Instituto de Ciências Biomédicas, Universidade de São Paulo, São Paulo, 2016.

Cervical cancer is the forth most frequent cancer in women worldwide, and it is the seventh more common in general population. The main factor for developing these tumors is the infection with human papillomavirus (HPV). HPV tumors recruit leucocytes and change their phenotype as an evasion mechanism. The inflammatory infiltrate modulation has been studied as a possible anti tumor therapy; however, the tumor mechanisms that influence the immune cells phenotype are not complete characterized. It is important to understand the tumor chronic signs effects responsible for alterations in signaling pathways that may be beneficial to the tumor growth. In this study, we tried to understand how the tumor might influence the immune cells behavior, analyzing signaling pathways related to proliferation, survival and immune response. Biopsy and peripheral blood mononuclear cells (PBMC) from patients with high-grade lesion and cancer were analyzed, together with PBMC from health woman, as control. There was an increase in the biopsy inflammatory infiltrate from patients with cancer when compared with the high-grade lesions ones. Most of the inflammatory infiltrate is non-activated $T$ lymphocytes. The inflammatory infiltrate has a higher total NFKB expression than the tumor cells in both patients. The total NFKB expression in both patients is similar, but the biopsy immune cells from patients with cancer have a higher phospho p65 expression than the patients with high-grade lesions. We could not find any difference in the STAT3 proteins expression in the biopsy cells. Meanwhile the total and phospho Akt expression was higher in the biopsy cells from cancer patients than the high-grade lesions ones. When the systemic effect was evaluated, we found a small percentage of $T$ lymphocytes in cancer patients than in control group. We could observe a decrease in the total and phospho p65 expression in the total PBMC from patients compared with the control group. The cancer patients had an even more accentuated decreased than the high-grade lesions patients. On the other hand, the total PBMC from cancer patients had an increase in the STAT3 activation when compared with the control group; this increase was observed in the T lymphocytes, but not in the antigen presenting cells (APC). A similar response between cancer patients and the control group was observed related to the activation of Akt signaling pathway; but the augment observed in this signaling pathways was identified in the APC as well in the $T$ lymphocytes. In an attempt to identify a better immune response against the tumor effect in the APC from PBMC, as an immune therapy, we stimulated B lymphocytes from patients with $10 \mu \mathrm{g} / \mathrm{ml}$ of SCD $40 \mathrm{~L}$ and $20 \mathrm{ng} / \mathrm{ml}$ of IL-4 for 24 hours. The stimuli increase the number of $\mathrm{CD} 80^{+} \mathrm{CD} 86^{+}$cells. Our results demonstrate a tumor effect over the immune cells, with an important systemic effect. However, the approach used in this study to stimulate B lymphocytes from patients present us with a possible strategy to scape from the tumor influence.

Keywords: Cervical cancer. Human papillomavirus. Signaling pathways. NFKB. STAT3. Akt. B lymphocytes. 
INTRODUÇÃO 


\section{INTRODUÇÃO}

\subsection{Câncer cervical}

O câncer cervical é uma importante enfermidade que acomete milhares de mulheres anualmente. Segundo estimativas mundiais, o câncer do colo do útero é o quarto tipo de câncer mais frequente em mulheres, sendo o sétimo tipo mais comum na população em geral. Oitenta e cinco por cento dos casos estão em países em desenvolvimento, causando grande impacto nos programas de saúde pública devido ao alto grau de morbidade associado a essa doença e a necessidade de tratamento cirúrgico da mesma (GLOBOCAN, 2012). No Brasil, segundo dados do Instituto Nacional do Câncer, o carcinoma do colo uterino é o terceiro mais frequente na população feminina, e a quarta causa de morte de mulheres por câncer (INSTITUTO NACIONAL DO CÂNCER, 2016).

O principal fator etiológico associado ao câncer cervical é a infecção pelo Papilomavírus Humano (HPV) de alto risco oncogênico. Assim, o HPV é associado a virtualmente todas as ocorrências de câncer cervical, sendo detectado em 99,7\% dos casos (WALBOOMERS et al., 1999). Os HPV 16 e 18 juntos são responsáveis por $70 \%$ dos casos de câncer cervical, sendo também os dois tipos mais frequentes nas infecções assintomáticas (BRUNI et al., 2010; STANLEY, 2008). A infecção pelo HPV também é fator etiológico de uma porcentagem dos tumores anogenitas e orofaríngeos em homens e mulheres (CHATURVEDI et al., 2011).

Embora a infecção pelo vírus seja o principal fator de risco para o desenvolvimento do câncer, a maior parte das mulheres infectadas elimina a infecção espontaneamente. $O$ sistema imune tem importante papel na eliminação do vírus e das lesões precursoras de câncer, uma vez que pacientes imunodeficientes, como portadores de HIV, apresentam maior risco de desenvolvimento de lesões de alto grau e câncer (DUERR et al., 2001; PALEFSKY et al., 2001). Há também fatores relacionados ao comportamento que podem influenciar o desenvolvimento tumoral, como o número de parceiros sexuais, o uso de anticoncepcional oral por um longo período de tempo, o número de partos e uso de álcool e/ou tabaco (PARKIN; BRAY, 2006; SCHLECHT et al., 2001). 
As lesões precursoras são classificadas pelo sistema Bethesda, através da análise citológica cérvico-vaginal que tem como objetivo facilitar a interpretação dos resultados tornando os termos menos ambíguos, além de aproximá-los do vocabulário das pacientes. Tal sistema define como lesões de baixo grau as alterações celulares devidas ao HPV como a displasia leve (Neoplasia Intraepitelial Cevical-I, ou seja, NIC-I), e unifica sob o termo de lesão de alto grau a displasia moderada (NIC-II), a displasia acentuada (NIC-III) e o carcinoma in situ (NIC-III) (APGAR; ZOSCHNICK; WRIGHT, 2003; SOLOMON et al., 2002).

O estadiamento dos carcinomas cervicais são classificados pelo sistema FIGO, do Italiano, Fesddration Internationale des Gynaecologistes et Obstetristes. O estadiamento é uma forma de descrever o câncer, identificando sua localização, se está disseminado, e se está afetando as funções de outros órgãos, possibilitando assim, a melhor decisão sobre o tratamento de cada paciente. Há 5 estágios no câncer cervical:

- Estágio 0, o tumor encontra-se apenas na superfície do colo uterino, equivale ao carcinoma in situ.

- Estágio I, o tumor ainda se encontra localizado no colo uterino, mas não apenas na superfície, não há invasão a outros tecidos e não há disseminação para os linfonodos vizinhos.

- Estágio II, o tumor já ultrapassa o colo uterino, mas não se disseminou para as paredes da pelve ou parte inferior da vagina, não há comprometimento dos linfonodos vizinhos.

- Estágio III, o tumor se disseminou para a parte inferior da vagina e/ou paredes da pelve, podendo bloquear os ureteres. Na subclassificação em Estágio IIIB já há comprometimento dos linfonodos da pélvis.

- Estágio IV, o tumor se encontra disseminado podendo estar mais localizado nas regiões próximas, como bexiga e reto (Estágio IVA) ou com comprometimento de órgãos distantes da região pélvica, como pulmão e fígado (Estágio IVB).

Das mulheres infectadas pelo vírus 12\% desenvolvem lesão de baixo grau, sendo que dessas apenas $10 \%$ progridem para lesão de alto grau. Das mulheres com lesão de alto grau, apenas 10\% irão progredir para o desenvolvimento do câncer cervical, dessa forma, apenas $0,1 \%$ das mulheres infectadas pelo HPV 
desenvolvem o tumor (SCHLECHT et al., 2001). Embora a porcentagem de mulheres que desenvolvem o tumor seja pequena, o valor absoluto é alto devido ao grande número de mulheres infectadas pelo vírus. A taxa de infecção pelo vírus é em torno de 20 a $40 \%$ em mulheres sexualmente ativas na faixa dos 20 anos. Essa taxa vai diminuindo conforme o aumento da idade das mulheres (BASEMAN; KOUTSKY, 2005).

\subsection{Papilomavírus Humano}

Os Papilomavírus são uma família de pequenos vírus de DNA circular dupla-fita não envelopado com genoma de aproximadamente $7.9 \mathrm{~kb}$, que codifica dependendo do tipo viral até 8 genes, envolvido em um capsídeo icosaédrico. O genoma do HPV é composto por três regiões (Figura 1), uma região reguladora, denominada LCR (do inglês, Long Control Region), uma região de genes que codificam proteínas precoces, E1 a E7, e uma região de genes que codificam proteínas consideradas tardias no ciclo viral, L1 e L2. As proteínas tardias são proteínas estruturais do capsídeo do vírus, já as proteínas precoces estão envolvidas com diversas funções virais, inclusive mecanismos de evasão do sistema imune. As proteínas E6 e E7 são classificadas como oncoproteínas (BOCCARDO; LEPIQUE; VILLA, 2010; DOORBAR et al., 2012). 
Figura 1 - Ilustração do genoma do HPV 16.

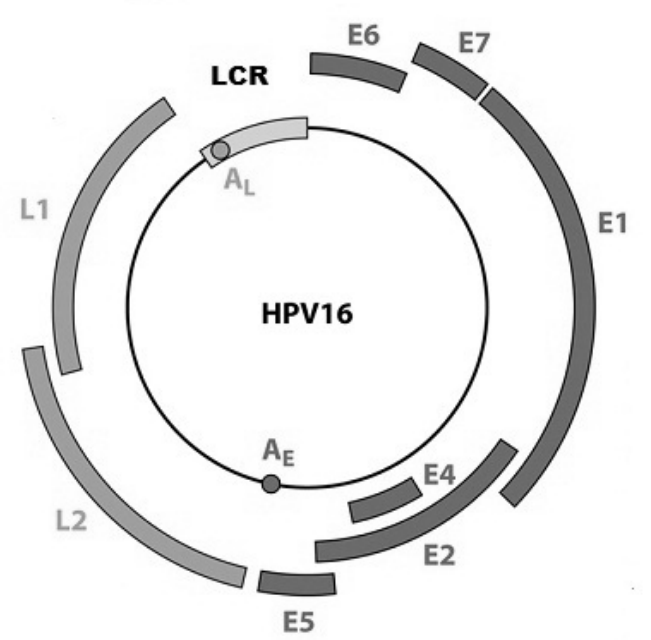

Representação do genoma do HPV16. Esse genoma contém uma região precoce, composta pelos genes E1 a E7, que codificam proteínas envolvidas nas funções virais; e uma região tardia, composta pelos genes L1 e L2, que codificam proteínas virais estruturais do capsídeo. O controle da transcrição e replicação dos genes precoces é conferido pela região LCR. Figura modificada de Quint et al, 2012.

Os HPVs infectam pele ou mucosas de forma específica, sendo subdivididos em genêros. O genêro Betapapillomavirus compreende os tipos de HPV prevalentes em lesões cutâneas, que em alguns casos, podem contribuir para o desenvolvimento de câncer de pele não-melanômico. Já os do gênero Alphapapillomavirus, são principalmente associados a infecções do trato anogenital e orofaríngeo e ainda são subdivididos em tipos de baixo e alto risco de acordo com seu potencial oncogênico. Os de baixo risco oncogênico geram lesões benignas, como verrugas, papilomas anogenitais e papilomas orofaríngeos, enquanto os tipos virais de alto risco apresentam os mais eficientes mecanismos de evasão do sistema imune e de imortalização de queratinócitos, levando o desenvolvimento de lesões malignas (DOORBAR, 2005; VILLIERS et al., 2004). Os HPV de baixo risco mais comuns nas lesões anogenitais são os tipos 6 e 11, enquanto que os HPV de alto risco mais frequentemente encontrados em lesões malignas são tipos 16 e 18.

O ciclo viral do HPV não é citolítico. O vírus infecta os queratinócitos da camada basal, e tem seu ciclo de vida intimamente associado ao processo de diferenciação natural para sua replicação. As principais proteínas virais envolvidas diretamente na replicação viral são E1 e E2, sendo que E2 também controla a transcrição dos genes precoces virais (DOORBAR et al., 2012; FRATTINI; LAIMINST, 1994; GOODWIN et 
al., 1998). Durante a fase inicial do ciclo, o DNA viral se mantém epissomal e a proteína E2 mantem uma baixa expressão dos oncogenes E6 e E7 (JEON; LAMBERT, 1995; ROMANCZUK; HOWLEY, 1992). Conforme os queratinócitos vão se diferenciando o vírus vai se replicando lentamente, aumentando sua replicação em até 10 vezes assim que os queratinócitos alcançam a camada supra-basal, nessa fase há expressão aumentada dos genes E6 e E7, além da expressão dos genes tardios, para então ocorrer a liberação de novas partículas virais (DOORBAR et al., 2012).

Enquanto em infecções produtivas o genoma viral se mantem epissomal, em infecções persistentes existe o risco da integração do genoma viral ao genoma da células hospedeira. A integração do genoma viral ao genoma do hospedeiro ocorre ao acaso, sem preferência por um sítio específico do DNA, entretanto dependendo do local da integração do genoma viral a célula infectada tem vantagens adaptativas sobre as outras (ZIEGERT et al., 2003). A imortalização da células pode ocorrer quando, durante a integração do genoma viral, há preservação da região reguladora e dos oncogenes E6 e E7, com quebra ou perda de parte do gene E2. Dessa forma, a expressão de E6 e E7 torna-se constitutiva (DOORBAR et al., 2012).

Nos tumores associados ao HPV, as proteínas codificadas pelos oncogenes virais E6 e E7 do HPV de alto risco têm papel essencial na manutenção do fenótipo transformado das células (GOODWIN; DIMAIO, 2000). As proteínas E6 e E7 são as principais responsáveis pela imortalização dos queratinócitos infectados, evento inicial no processo de transformação tumoral, e pelos principais mecanismos de evasão do sistema imune (TINDLE, 2002). A oncoproteína E6 é responsável pela inativação e degradação de p53 através da ligação com a proteína E6AP, uma subunidade E3 do sistema proteassoma (SCHEFFNER et al., 1990). Além disso, a proteína E6 aumenta a transcrição de hTERT, subunidade catalítica da telomerase com função de manter a integridade dos telômeros durante a replicação de genoma celular, possibilitando assim a imortalização da célula infectada (BRANCA et al., 2006; KLINGELHUTZ; FOSTER; MCDOUGALL, 1996). Já a oncoproteína E7 é capaz de se associar com proteínas hipofosforiladas da família retinoblastoma (pRB), levando a degradação de p105, p107 e p130, e aumentando a concentração de fatores E2F livres, que por sua vez, induzem a expressão de genes que controlam a progressão do ciclo celular (JOHUNG; GOODWIN; DIMAIO, 2007). 
Assim, devido ao papel conjunto de E6 e E7 há continuidade do ciclo celular, mesmo com acúmulo de mutações.

\subsection{Sistema Imune e HPV}

A importância do sistema imune tanto na resposta frente a infecção pelo HPV quanto em relação a progressão da doença pode ser evidenciada em estudos epidemiológicos, uma vez que pacientes imunodeficientes apresentam maior risco de infecção pelo vírus e também de desenvolver lesões de alto grau e câncer (DUERR et al., 2001; PALEFSKY et al., 2001).

Nas lesões associadas ao HPV observa-se um aumento crescente do número de macrófagos conforme a progressão da doença. A presença de macrófagos tipo 1 (M1) é um indicador de bom prognóstico para a paciente (MAZIBRADA et al., 2008). Os macrófagos M1 são caracterizados pela secreção de citocinas pró-inflamatórias (TNF-a, IL-1, IL-6, IL-12), além da produção de espécies reativas de oxigênio e nitrogênio. Entretanto estudos indicam que os macrófagos tumorais geralmente não expressam iNOS (MUNN; MELLOR, 2007), assemelhando-se ao fenótipo tipo 2 (M2). Os macrófagos M2 são caracterizados pela secreção de citocinas antiinflamatórias (IL-4, IL-10, TGF- $\beta$ ) e expressão de Arginase 1. Nosso laboratório demonstrou, em modelo murinho de tumor associado ao HPV, a ausência da expressão de iNOS e a atividade constitutiva de Arginase 1 nos macrófagos que infiltram o tumor. Tais macrófagos expressam IL-10 e TGF- $\beta$, e induzem fenótipo regulador em linfócitos T (LEPIQUE et al., 2009). A depleção dos macrófagos ou a deficiência de IL-10 inibem o crescimento tumoral (BOLPETTI et al., 2010).

Observa-se também a redução do número de células dendríticas nas lesões associadas ao HPV, devido, principalmente, à redução da expressão de E-Caderina em queratinócitos infectados (HUBERT et al., 2005). Além disso, as células dendríticas tumorais expressam Indoleamina 2,3 dioxigenase (MUNN; MELLOR, 2007), sabidamente um indutor de fenótipo regulador em células T.

A exposição das células apresentadoras de antígenos ao vírus ou as células tumorais influenciam o tipo de fenótipo das células $\mathrm{T}$ a ser desenvolvido. Demonstrou-se que linfócitos $\mathrm{T} \mathrm{CD}^{+}$de mulheres positivas para DNA de HPV, porém assintomáticas, respondem a antígenos de HPV proliferando e secretando 
IFN-y, IL-2, IL-5, TNF-a, IL-10 (JONG et al., 2004; WELTERS et al., 2006). Já linfócitos de mulheres com câncer proliferam pouco em resposta a antígenos de HPV, produzindo apenas IL-10. Além disso células $\mathrm{T}$ reguladoras específicas aos antígenos do HPV inibem a resposta de células T efetoras específicas (BURG et al., 2007). O desenvolvimento da resposta citotóxica é fundamental no combate tanto das células infectadas pelo vírus, como também das células tumorais, entretanto, a resposta de linfócitos T CD8 ${ }^{+}$é muitas vezes deficiente nas pacientes com lesões de alto grau do colo uterino (TRIMBLE et al., 2010). Um dos mecanismos responsáveis por essa fraca resposta dos linfócitos $T$ citotóxicos é a diminuição da expressão do MHC de classe I nas células infectadas pelo vírus. A proteína viral E5 leva a retenção das proteínas do HLA A, B e C no complexo de Golgi, impedindo assim, o seu transporte para a membrana celular, evitando assim a apresentação de antígenos virais para linfócitos T CD8 ${ }^{+}$(ASHRAFI et al., 2005). Já os complexos E e G não são impedidos de chegar à membrana das células infectadas, evitando a resposta citotóxica de células NK. O importante papel dos linfócitos $T$ foi demonstrado em um estudo que avaliou pacientes quanto ao risco de metástase no linfonodo drenante. As pacientes que não apresentavam metástase no linfonodo, um fator relacionado a um melhor prognóstico, apresentavam uma associação com um maior número de linfócitos $\mathrm{T}_{\mathrm{CD}}{ }^{+}$infiltrantes no tumor, além de apresentarem maiores razões entre $\mathrm{T} \mathrm{CD}^{+} / \mathrm{T} \mathrm{CD}^{+}$e $\mathrm{T} \mathrm{CD}^{+} / \mathrm{T}$ reguladora, também, no tumor (PIERSMA et al., 2007).

A resposta humoral no câncer cervical não se encontra associada com o prognóstico da paciente. Durante a infecção viral, há uma baixa e demorada produção de anticorpos contra as proteínas do capsídeo viral. Embora esses anticorpos não tenham papel na eliminação da infecção em curso, eles são capaz de proteger da doença em uma futura infecção (PATEL; CHIPLUNKAR, 2009; STANLEY, 2010). Foi demostrando que os anticorpos contra a proteína L1, do capsídeo viral, são capazes de permanecer no organismo por até 10 anos (GEIJERSSTAM et al., 1998). A resposta humoral contra as oncoproteínas E6 e E7, ocorre em apenas $50 \%$ das pacientes com câncer cervical, sendo o título dessa resposta bastante baixo (SILINS et al., 2002).

O HPV apresenta diversos mecanismos de evasão do sistema imune impedindo, assim, o desenvolvimento de uma resposta efetora eficiente contra os antígenos 
virais (BOCCARDO; LEPIQUE; VILLA, 2010). Em uma infecção, a entrada do capsídeo viral é percebida pelas células de Langerhans, com objetivo de montar uma resposta imunológica. Entretanto, estudos demonstram que o reconhecimento da proteína L1 do capsídeo viral pelas células de Langerhans não é capaz de levar uma ativação nessas células (FAUSCH et al., 2015). Outro mecanismo de evasão está relacionado a produção de Interferons do tipo I (IFN- $\alpha$ e IFN- $\beta$ ), que induzem respostas anti-virais (HERDMAN et al., 2006; PATEL; CHIPLUNKAR, 2009). As proteínas E6 e E7 interagem diretamente com componentes da via de sinalização que leva a expressão de genes alvos de Interferon tipo I. A proteína E7 interage com IRF-1 (Interferon Regulatory Factor-1) inibindo sua atividade e a proteína E6 inibe a atividade transcricional de IRF-3, tais ações levam à diminuição da expressão de IFN- $\beta$ (ANTONSSON et al., 2006; RONCO et al., 1998; UM et al., 2002). O IFN- $\alpha$ também é inibido através da ligação da proteína E7 com IRF-9 (Antonsson, Payne et al. 2006). Outro mecanismo de evasão relacionado a via do Interferon foi identificado em um estudo com células epiteliais cervicais que contêm cópias epissomais do HPV-16. Demonstrou-se que o IFN- $\beta$ ao eliminar as células com o DNA epissomal, acaba selecionando as células com o DNA viral integrado e alta expressão dos oncogens E6 e E7 (HERDMAN et al., 2006).

\subsection{Inflamação crônica e Câncer}

Tumores são estruturas complexas formadas por vários tipos celulares. A combinação de células tumorais, células endoteliais, fibroblastos, elementos acelulares e células do sistema imunes forma o microambiente tumoral. $\mathrm{O}$ tumor promove o condicionamento das células inflamatórias, e de todas as outras presentes no microambiente tumoral, criando um ambiente favorável à sua progressão (HANAHAN; WEINBERG, 2011). Assim, a inflamação, antes uma resposta protetora fundamental para o organismo, tem no seu descontrole um importante cofator na patogenicidade de doenças crônicas como o câncer, sendo atualmente definida como a sétima marca do câncer (BEN-NERIAH; KARIN, 2011a; CAVALLO et al., 2011). Rudolf Virchow demonstrou, em 1858, a presença de leucócitos no tecido neoplásico, associando assim inflamação e câncer. Através da produção de citocinas e quimiocinas o tumor leva o recrutamento de células do 
sistema imunológico, as quais serão influenciadas pelo tumor a produzirem fatores de crescimento, de sobrevivência e fatores pró-angiogênicos, resultando na amplificação da produção de citocinas e quimiocinas no microambiente tumoral (CHEN et al., 2006; COUSSENS; WERB, 2002). O infiltrado inflamatório torna-se um importante mediador da promoção e progressão tumoral (KARIN; GRETEN, 2005).

Há fortes evidências do papel da inflamação na susceptibilidade tumoral. Indivíduos que usam drogas anti-inflamatórias não esteroidais tem incidência reduzida de tumores, enquanto, pacientes obesos (inflamação gerada pelo tecido adiposo) apresentam maior incidência de câncer (TRINCHIERI, 2012). As doenças inflamatórias do intestino, como colite e doença de Crohn, apresentam forte associação com o câncer de intestino (BALKWILL; COUSSENS, 2004).

Atualmente acredita-se que aproximadamente $20 \%$ dos casos de câncer estão associados a infecção por patógenos. Embora alguns patógenos sejam capazes de induzir diretamente a transformação celular, outros favorecem a carcinogênese induzindo inflamação crônica no local. O câncer gástrico, por exemplo, está intimamente relacionado à inflamação resultante da infecção crônica por Helicobacter pylori. Já o câncer hepático está associado a infecção crônica pelos Vírus da Hepatite B e C.

O papel da inflamação crônica no desenvolvimento do câncer cervical ainda não está bem estabelecido. Há fortes evidências associando a inflamação na promoção e progressão tumoral. Em modelo murino verificou-se que a deposição de anticorpos no tecido tumoral leva o recrutamento de células inflamatórias, as quais são diretamente responsáveis pela progressão tumoral (VISSER; KORETS; COUSSENS, 2005). Os linfócitos B têm sido considerados, em diferentes estudos, pró-tumorais, em geral devido à expressão de citocinas reguladoras como IL-10 (TAN; COUSSENS, 2007). Entretanto, vale lembrar que linfócitos B são células apresentadoras de antígenos profissionais, incapazes de ativar linfócitos $\mathrm{T}$ naive, mas capazes de ativar respostas secundárias em linfócitos previamente ativados.

Sabe-se, também, que células HPV positivas secretam grandes quantidades de IL-6 e IL-8, importantes citocinas pró-inflamatórias (STONE et al., 2014a). Em contra partida, o microambiente tumoral tem grande quantidade de IL-10, uma citocina supressora da resposta imune (BOLPETTI et al., 2010). 


\subsection{Vias de Sinalização}

Câncer é uma doença crônica caracterizada por alterações genéticas e epigenéticas que desencadeiam um crescimento celular descontrolado, escapando de mecanismos de controle da sobrevivência e migração celular (SEVER; BRUGGE, 2015). Durante a progressão da doença, as células tumorais adquirem características como a capacidade de proliferação independente de fatores de crescimento externos, de invadir tecidos adjacentes e de migrar para sítios distantes (HANAHAN; WEINBERG, 2011). Todas essas novas características refletem alterações nas vias de sinalização que em células normais controlariam a proliferação, sobrevivência e motilidade celular. O microambiente tumoral é complexo, composto não apenas por células tumorais como também, por células do sistema imune, células endoteliais e fibroblastos. Citocinas produzidas por um tipo celular são percebidas pelas outras células participantes desse ambiente desencadeando uma possível resposta pró ou antitumoral. O acúmulo de sinais durante anos do desenvolvimento tumoral leva uma subversão das vias de sinalização em todas as células do microambiente tumoral (MARTIN, 2003). Nosso estudo foca-se na avaliação de três vias de sinalização, importantes no desenvolvimento da resposta imune e no controle da proliferação e sobrevivência celular.

\subsubsection{NFKB}

NFKB é um fator de transcrição responsável pela regulação de muitos genes envolvidos na resposta imunológica e inflamatória. A ativação clássica de NFkB é induzida por citocinas pró-inflamatórias, como TNF- $\alpha$ e IL-1, e também pelo reconhecimento de patógenos por receptores de padrões moleculares. A via alternativa da ativação de NFKB está envolvida com o desenvolvimento de órgãos linfoides, sendo fundamental para o desenvolvimento de respostas adaptativas pelo organismo (BONIZZI; KARIN, 2004). A família de NFKB é composta por cinco membros: p65 (também conhecida por RelA), RelB, c-Rel, p50 (que tem como precursor a proteína p105) e p52 (que tem como precursor a proteína p100). A proteína NFKB é formada pela combinação dos membros da família, podendo ser 
encontrada como heterodímeros, ou menos frequentemente, como homodímeros. A função de NFKB é determinada pela composição do dímero. Cada dímero se liga a um sítio específico de transcrição. A maioria dos dímeros são ativadores da transcrição, entretanto os homodímeros de p50 e p52, atuam como repressores da transcrição (GHOSH; KARIN; HAVEN, 2002).

O complexo NFKB é mantido no citoplasma da célula pelo seu inibidor IkB. Após um sinal de ativação, o complexo IKK fosforila a proteína IKB que se encontra ligado ao complexo NFKB. A proteína IkB torna-se, então, um alvo para a ubiquitinização, e consequentemente é degradada pelo complexo proteassoma. $A$ degradação do IKB, expõe uma sequencia de localização nuclear no complexo NFKB, resultando na sua translocação para o núcleo (CHEN; GREENE, 2004; GHOSH; HAYDEN, 2012). A translocação do complexo NFKB para o núcleo não é suficiente para promover a máxima função do complexo, modificações pós-traducionais são necessárias. A modificação pós-traducional mais estudada é a fosforilação de p65 na serina 536 . Além dessa modificação ser importante para o aumento da capacidade de ligação do complexo com o DNA, ela também é responsável por criar um sítio de interação da proteína p65 com o co-ativador transcricional CBP/p300 (ZHONG; VOLL; GHOSH, 1998).

A ativação de NFKB tem sido encontrada em diversos tumores sólidos. Acreditase que NFKB tenha importante papel na tumorigênese aumentando a inflamação local, tornando o microambiente tumoral favorável a progressão da doença (BENNERIAH; KARIN, 2011b; KARIN; GRETEN, 2005). Além disso, o aumento na ativação da via de NFKB tem sido associada a resistência ao tratamento com quimioterápicos (KARIN; GRETEN, 2005; SHEHATA, 2005). O fator de transcrição NFKB também está associado a homeostase epidermal, agindo como um regulador negativo da proliferação e promotor da diferenciação celular (SEITZ et al., 1998). A superexpressão do inibidor IKB na pele de camundongos levou um aumento na quantidade de células apoptóticas e o desenvolvimento espontâneo de carcinoma (HOGERLINDEN et al., 1999). Tal mecanismo também foi observado em culturas de células epidermais humanas (DAJEE et al., 2003).

O papel da via de NFkB nos leucócitos durante a progressão tumoral não está bem descrito. A via de NFkB é essencial na ativação da expressão de moléculas coestimuladoras, importantes para ativação de linfócitos $T$, e de citocinas que induzem 
fenótipo citotóxico, por exemplo, IL-12 (FONG; WU; KIPPS, 1996; MURPHY et al., 1995; YOSHIMURA et al., 2001; ZOU; HU, 2005). Em modelo experimental, nosso laboratório demonstrou que o tumor associado ao HPV 16 é capaz de inibir a via de NFkB, em um mecanismo dependente da citocina IL-10 (STONE et al., 2014b). Uma das formas de ativação da via de NFkB é a utilização do ligante ou agonista do receptor CD40. CD40 é um receptor da família do TNF-a, expresso por células apresentadoras de antígenos profissionais, e seu ligante, CD40L, é expresso por linfócitos $T$ ativados. A interação entre os linfócitos $T$ e células apresentadoras de antígenos leva tanto ao estímulo do linfócito T, como ao da célula apresentadora, induzindo nestas a expressão de moléculas co-estimuladoras e citocinas. Nosso laboratório identificou uma melhora no potencial de apresentação antigênica em linfócitos B de camundongos com tumores associados ao HPV 16 estimulados com agonista de CD40, revertendo, assim, o efeito do tumor sobre essas células (manuscrito em anexo).

\subsubsection{STAT3}

A maioria dos tumores tem elevado nível de STAT3 constitutivamente ativado no núcleo tanto de células tumorais, como no de células inflamatórias presentes no microambiente tumoral. A ativação de STAT3 leva a transcrição de genes que bloqueiam a apoptose, favorecem a proliferação e sobrevivência celular, além de promoverem a angiogênese e metástase tumoral (JOHNSTON; GRANDIS, 2011; TRINCHIERI, 2012). Além disso, os genes alvos de STAT3 tem importante papel na supressão do sistema imune. A ativação de STA3 leva a uma diminuição na produção de IL-12 e TNF- $\alpha$ e um aumento da produção de IL-6, IL-10 e TGF- $\beta$. Importantes moléculas da apresentação de antígenos, CD80, CD86 e MHC-II, também são moduladas negativamente pelos genes alvos de STAT3 (CARPENTER; LO, 2014).

A ativação de STAT3 ocorre através de receptores de citocinas, como a IL-6 e de fatores de crescimento, como o EGF. A dimerização dos receptores induzidos pelo reconhecimento do seu ligante leva a fosforilação de resíduos tirosina na glicoproteína 130, adjacente ao complexo, pelas quinases JAK1 e JAK2. Esse recentes sítios de fosforilação permitem o ancoramento da proteína STAT3 através 
do domínio SH2 (WANG et al., 2013). A ligação da proteína STAT3 com o complexo do receptor de citocina, leva à fosforilação do resíduo de tirosina 705 na região Cterminal da proteína STAT3, promovendo a sua homodimerização. $\mathrm{Na}$ forma homodimérica, STAT3 se transloca para o núcleo onde se ligará a sítios específicos do DNA, levando assim, à transcrição de seus genes alvos (JOHNSTON; GRANDIS, 2011). Uma segunda fosforilação, no resíduo de serina 727 , já no núcleo, irá modular a atividade transcicional de STAT3 (YANG et al., 2005). A ativação de STAT3 é transiente, pois é rapidamente regulada negativamente pelas proteínas SOCS (do inglês, Supressor of Cytokine Signaling) (YU; KORTYLEWSKI; PARDOLL, 2007). As proteínas SOCS também são induzidas por citocinas e fatores de crescimento, em um clássico mecanismo de feed-back negativo. O próprio fator de transcrição STAT3 induz a produção de proteínas SOCS (WANG et al., 2013).

A proteína STAT3 é encontrada ativa e superexpressa em diversos tipos de tumores (CHEN et al., 2007), no câncer cervical está relacionada a um pior prognóstico da paciente (TAKEMOTO et al., 2009). A citocina IL-6, encontrada em abundância no microambiente tumoral, é importante na patogenicidade do câncer cervical, sendo associada com a severidade da doença. A ativação de STAT3 pela citocina IL-6 é responsável pelo aumento da atividade angiogênica local através do aumento na produção de VEGF (WEI et al., 2003). STAT3 também é responsável por regular a expressão de fatores de transcrição relacionados a transição epitéliomesênquima, como Twist e Snail. O fator de transcrição Twist tem como um dos genes alvos a citocina IL-6, formando assim um interessante feed-back positivo nas células tumorais: a citocina IL-6 leva a ativação de STAT3, que induz a expressão de Twist, que leva a um aumento na produção de IL-6 (MURRAY, 2016).

A análise de linhagens positivas para HPV 16 e lâminas de biópsias de câncer no colo uterino observou uma correlação positiva entre a proteína STAT3 ativada e a expressão das proteínas E6 e E7 do HPV. Observou também, uma correlação negativa com a expressão das proteínas p53 e pRb. A inibição da fosforilação na tirosina 705 em STAT3 nas linhagens celulares resultou em um acúmulo de p53 e pRb e uma diminuição na expressão de E6 e E7 (SHUKLA et al., 2013). 


\subsubsection{Akt}

A quinase serina/treonina Akt, também conhecida por proteína quinase $B(P K B)$, tem um importante papel na sinalização celular de citocinas, fatores de transcrição e outros estímulos celulares. Alterações na ativação desta via são comumente encontradas em doenças como o câncer. A formação de PIP3 (fosfatidilinositol3,4,5-trifosfato) a partir de PIP2 (fosfatidilinositol-4,5-bifosfato) pela enzima PI3K (fosfatidilinositol-3-quinase), recruta a proteína Akt para a membrana celular. $\mathrm{Na}$ membrana celular a quinase PDK1 fosforila Akt no resíduo de treonina 308, levando a uma ativação de Akt. Para a máxima ativação de Akt ocorrer, é necessário uma segunda fosforilação no resíduo serina 473 , dessa vez pela quinase PDK2 (CANTLEY, 2002; VIVANCO; SAWYERS, 2002). A proteína PTEN irá desfosforilar PIP3, impedindo o ancoramento da proteína Akt na membrana celular, funcionando como um regulador negativo da via. As principais consequências da ativação de Akt estão relacionadas ao crescimento, sobrevivência e proliferação celular. O controle da sobrevivência celular é realizado principalmente através da inibição da apoptose. Entretanto, a proteína Akt também pode agir diretamente no controle do ciclo celular. A proteína Akt impede a degradação da ciclina D1, responsável pela progressão do ciclo celular da fase $\mathrm{G} 1$ para a $\mathrm{S}$. A quinase mTOR responsável por regular a síntese proteica de nutrientes, regulando assim o crescimento celular, é um alvo direto de Akt (VIVANCO; SAWYERS, 2002).

A hipóxia é um stress no microambiente tumoral, influenciando a sinalização e funções celulares. Em tumores sólidos a hipóxia está associada ao pior prognóstico da paciente após o tratamento com radioterapia (STEGEMAN et al., 2012). Estudos demonstram que a hipóxia tumoral induz a ativação de Akt via PI3K, levando a uma maior resistência a apoptose nas células tumorais. A inibição da ativação de Akt leva a um aumento da morte celular nas células tumorais hipotóxicas, mas não nas células tumorais em normóxia (ALVAREZ-TEJADO et al., 2001). A via PI3K/Akt induz a expressão do fator de transcrição HIF-1a (PORE et al., 2006).

Diversos trabalhos mostram a relação desta via com o câncer do colo uterino, demonstrando uma correlação positiva entre sua ativação e o desenvolvimento tumoral (HENKEN et al., 2011; MA et al., 2000). Em culturas organotípicas, a oncoproteína E7 do HPV leva a um aumento na ativação de Akt, via pRb (MENGES 
et al., 2006). Além disso, a via PI3K/Akt está associada a maior resistência ao tratamento com quimioterapia e radioterapia. Estudos iniciais utilizando inibidores de Akt em conjunto com os tratamentos convencionais têm apresentado resultados bastante promissores (GAIKWAD; RAY, 2012). O tratamento com o inibidor da PI3K, LY294002, não leva a diminuição da sobrevivência das células tumorais, entretanto, ele as torna mais sensíveis ao tratamento com radiação (LEE et al., 2006). 
CONCLUSÕES 


\section{CONCLUSÕES}

$\checkmark$ Há acúmulo do infiltrado inflamatório nas biópsias das pacientes com câncer quando comparadas com as biópsias das pacientes com lesão de alto grau. A maioria das células do infiltrado inflamatório encontradas nas biópsias são linfócitos T não ativados.

$\checkmark$ Há diminuição na proporção de linfócitos $T$ circulantes nas pacientes com câncer quando comparadas com as mulheres sem indicação de lesão no colo uterino. Essa alteração pode ser devida ao aumento de células mielóides circulantes induzido por citocinas secretadas pelo tumor.

$\checkmark \quad \mathrm{O}$ infiltrado inflamatório das biópsias das pacientes tem maior expressão da proteína NFKB total do que as células CD45. Embora a expressão da proteína total seja semelhante entre as amostras das pacientes com lesão de alto grau e câncer, o infiltrado inflamatório das biópsias das pacientes com câncer tem aumento na expressão da proteína p65 em relação ao infiltrado inflamatório das biópsias das pacientes com lesão de alto grau.

$\checkmark$ Há uma diminuição nas expressões das proteínas NFKB total e p65 fosforilada nas células mononucleares das pacientes quando comparadas com o grupo controle. Essa diminuição é ainda mais acentuada nas células mononucleares das pacientes com câncer do que nas pacientes com lesão de alto grau. Essa diminuição é refletida nas dois tipos celulares analisados, as células apresentadoras de antígeno e os linfócitos $T$.

$\checkmark$ Embora não haja diferença na expressão de STAT3 nas biópsias das pacientes com lesão de alto grau e câncer, observa-se a formação de grupos bem definidos com maior e menor expressão das proteínas. Devido ao pequeno número de pacientes, nós não conseguimos relacionar o nível de expressão de STAT3 e o estadiamento do tumor. 
$\checkmark$ As células mononucleares das pacientes com câncer tem maior expressão da proteína STAT3 fosforilada do que as mulheres sem indicação de lesão no colo uterino. Ao analisar as subpopulações das células mononucleares dessas pacientes, observa-se esse mesmo aumento nos linfócitos $T$, mas não nas células apresentadoras de antígeno.

$\checkmark$ Tanto o infiltrado inflamatório, quanto as células tumorais das biópsias das pacientes com câncer tem aumento na expressão das proteínas Akt total e fosforilada em relação as células das biópsias das pacientes com lesão de alto grau.

$\checkmark$ As células mononucleares do sangue periférico das pacientes com câncer tem maior expressão da proteína Akt fosforilada do que as células do grupo controle. Esse aumento é observado tanto nas células apresentadoras de antígeno, quanto nos linfócitos T.

$\checkmark$ O estímulo com $10 \mu \mathrm{g} / \mathrm{ml}$ de SCD40L e $20 \mathrm{ng} / \mathrm{ml}$ de IL-4 por 24 horas aumentou a expressão da molécula HLA-DR e o número de células duplo positivas para CD80 e CD86 em linfócitos $B$ de mulheres sem indicação de lesão no colo uterino. Esse mesmo estímulo foi capaz de aumentar o número de células duplo positivas para CD80 e CD86 em linfócitos B de pacientes com lesão de alto grau e câncer. 
REFERÊNCIAS 


\section{REFERÊNCIAS*}

ALVAREZ-TEJADO, $M$. et al. Hypoxia induces the activation of the phosphatidylinositol 3-Kinase / Akt cell survival pathway in PC12 cells. The Journal of Biological Chemistry, v. 276, n. 25, p. 22368-22374, 2001.

ANGUILLE, S. et al. Clinical use of dendritic cells for cancer therapy. The Lancet Oncology, v. 15, n. 7, p. 257-267, 2014.

ANTONSSON, A. et al. The human papillomavirus type 16 E7 protein binds human interferon regulatory factor-9 via a novel PEST domain required for transformation. Journal of Interferon and Cytokine Research, v. 461, p. 455-461, 2006.

APGAR, B. S.; ZOSCHNICK, L.; WRIGHT, T. C. The 2001 Bethesda system terminology. American Family Physician, v. 68, n. 10, p. 1992-1998, 2003.

ASHRAFI, G. H. et al. E5 protein of human papillomavirus type 16 selectively downregulates surface HLA class I. International Journal of Cancer, v. 283, p. 276-283, 2005.

BAILEY, S. R. et al. Th17 cells in cancer: the ultimate identity crisis. Frontiers in Immunology, v. 5, n. 276, p 1-13, 2014.

BALKWILL, F.; COUSSENS, L. M. An inflammatory link. Nature, v. 431, n. September, p. 405-406, 2004.

BASEMAN, J. G.; KOUTSKY, L. A. The epidemiology of human papillomavirus infections. Journal of Clinical Virology, v. 32, p. 16-24, 2005.

BANCHEREAU, J. et al. Long-term human B cell lines dependent on interleukin-4 and antibody to CD40. Science, v. 251, n. 4989, p. 70-72, 1991.

BELLEMORE, S. M. et al. Preventative role of interleukin-17 producing regulatory $T$ helper type 17 (Treg 17) cells in type 1 diabetes in non-obese diabetic mice. Clinical Experimental Immunology, v. 182, n. 3, p. 261-269, 2015.

BEN-NERIAH, Y.; KARIN, M. Inflammation meets cancer, with NF-KB as the matchmaker. Nature Immunology, v. 12, n. 8, p. 715-723, 2011 a.

BOCCARDO, E.; LEPIQUE, A. P.; VILLA, L. L. The role of inflammation in HPV carcinogenesis. Carcinogenesis, v. 31, n. 11, p. 1905-1912, 2010.

BOLPETTI, A. et al. Interleukin-10 production by tumor infiltrating macrophages plays a role in Human Papillomavirus 16 tumor growth BMC Immunology, v. 11, n. 27, 2010.

* De acordo com: ASSOCIAÇÃO BRASILEIRA DE NORMAS TÉCNICAS. NBR 6023: informação e documentação: referências: elaboração, Rio de Janeiro, 2002. 
BONIZZI, G.; KARIN, M. The two NF- kB activation pathways and their role in innate and adaptive immunity. TRENDS in Immunology, v. 25, n. 6, p. 280-288, 2004.

BRANCA, M. et al. Upregulation of telomerase (hTERT) is related to the grade of cervical intraepithelial neoplasia, but is not an independent predictor of high-risk human papillomavirus virus persistence, or disease outcome in cervical cancer. Diagnostic Cytopathology, v. 34, n. 11, p. 739-748, 2006.

BISHOP, G. A. The power of monoclonal antibodies as agents of discovery: CD40 revealed as a $B$ lymphocyte costimulator. The Journal of Immunology, v. 188, p. 4127-4129, 2012.

BRUNI, L. et al. Cervical human papillomavirus prevalence in 5 continents: metaanalysis of 1 Million women with normal cytological findings. The Journal of Infectious Diseases, v. 202, n. 12, p. 1789-1799, 2010.

BUNTING, K. et al. Genome-wide analysis of gene expression in T cells to identify targets of the NF-kB transcription factor c-rel. The Journal of Immunology, v. 178, p. 7097-7109, 2007.

BURG, S. H. VAN DER et al. Association of cervical cancer with the presence of CD4+ regulatory $T$ cells specific for human papillomavirus antigens. Proceeding of the National Academy Science U.S.A, v. 104, n. 29, p. 12087-12092, 2007.

CANTLEY, L. C. The phosphoinositide 3-kinase pathway. Science, v. 296, n. May, p. 1655-1658, 2002.

CARPENTER, R. L.; LO, H. STAT3 target genes relevant to human cancers. Cancers, v. 6, p. 897-925, 2014.

CAVALLO, F. et al. 2011: The immune hallmarks of cancer. Cancer Immunology, Immunotherapy, v. 60(3), p. 319-326, 2011.

CHATURVEDI, A. K. et al. Human papillomavirus and rising oropharyngeal cancer incidence in the United States. Journal of Clinical Oncology, v. 29, n. 32, p. 42944301, 2011.

CHEN, C. et al. Stat3 activation in human endometrial and cervical cancers. British Journal of Cancer, v. 96, p. 591-599, 2007.

CHEN, L.; GREENE, W. C. Shaping the nuclear action of NF-kB. Nature Reviews Molecular Biology, v. 5, n. May, p. 392-401, 2004.

CHEN, R. et al. Inflammation, cancer and chemoresistance : taking advantage of the toll-Like receptor signaling pathway. American Journal of Reproductive Immunology, v. 57, p. 93-107, 2006.

CORRIGAN-CURAY, J. et al. T-cell immunotherapy: looking forward. The American Society of Gene and Cell Therapy, v. 22, n. 9, p. 1564-1574, 2014. 
COUSSENS, L. M.; WERB, Z. Inflammation and cancer. Nature, v. 420, n. December, p. 860-867, 2002.

DILILLO, D. J.; YANABA, K.; TEDDER, T. F. B cells are required for optimal CD4+ and CD8+ $T$ cell tumor immunity: therapeutic B cell depletion enhances B16 melanoma growth in mice. The Journal of Immunology, v. 184, p. 4006-4016, 2016.

DOORBAR, J. The papillomavirus life cycle. Journal of Clinical Oncology, v. 32, p. 7-15, 2005.

DOORBAR, J. et al. The biology and life-cycle of human papillomaviruses. Vaccine, v. 30, p. F55-F70, 2012.

DUERR, A. et al. Human papillomavirus - associated cervical cytologic abnormalities among women with or at risk of infection with human immunodeficiency virus. American Journal of Obstetrics and Gynecology, v. 184, p. 584-590, 2001.

DYSON, N. et al. The human papilloma virus-16 E7 oncoproteins is able to bind to the retinoblastoma gene product. Science, v. 243, p. 934-937, 1989.

FAUSCH, S. C. et al. Human papillomavirus virus-like particles do not activate langerhans cells: a possible immune escape mechanism used by human papillomaviruses. The Journal of Immunology, v. 169, p. 3242-3249, 2015.

FONG, T. C.; WU, Y.; KIPPS, T. J. Identification of a promoter element that regulates tissue-specific expression of the human CD80 (B7.1) gene. The Journal of Immunology, v. 80, n. 157, p. 4442-4450, 1996.

FRATTINI, M. G.; LAIMINST, L. A. Binding of the human papillomavirus El originrecognition protein is regulated through complex formation with the E2 enhancerbinding protein. Proceeding of the National Academy Science U.S.A, v. 91, n. December, p. 12398-12402, 1994.

GAIKWAD, S. M.; RAY, P. Non-invasive imaging of PI3K / Akt / mTOR signalling in cancer. American Jornal of Nuclear Medice Molecular Imaging, v. 2, n. 4, p. 418431, 2012.

GEIJERSSTAM, V. et al. Stability over time of serum antibody levels to human papillomavirus type 16. The Journal of Infectious Diseases, v. 177, p. 1710-1714, 1998.

GHOSH, S.; HAYDEN, M. Celebrating 25 years of NF-kB Research. immunology Review, v. 246, n. 1, p. 5-13, 2012.

GHOSH, S.; KARIN, M.; HAVEN, N. Missing Pieces in the NF-kB Puzzle. Cell, v. 109, p. 81-96, 2002.

GOODWIN, E. C. et al. Transactivation-competent bovine papillomavirus E2 protein is specifically required for efficient repression of human papillomavirus oncogene 
expression and for acute growth inhibition of cervical carcinoma cell lines. Journal of Virology, v. 72, n. 5, p. 3925-3934, 1998.

GOODWIN, E. C.; DIMAIO, D. Repression of human papillomavirus oncogenes in HeLa cervical carcinoma cells causes the orderly reactivation of dormant tumor suppressor pathways. Proceeding of the National Academy Science U.S.A., v. 97, n. 23, p. 12513-12518, 2000.

HAGEMANN, T. et al. "Re-educating" tumor-associated macrophages by targeting NF-kappaB. Journal of Experimental Medicine, v. 205, n. 6, p. 1261-1268, 2008.

HANAHAN, D.; WEINBERG, R. A. Hallmarks of cancer: The next generation. Cell, v. 144, n.5 , p. 646-674, 2011.

HENKEN, F. E. et al. PIK3CA-mediated PI3-kinase signalling is essential for HPVinduced transformation in vitro. Molecular Cancer, v. 10, n. 1, p. 71, 2011.

HERDMAN, M. T. et al. Interferon-beta treatment of cervical keratinocytes naturally infected with human papillomavirus 16 episomes promotes rapid reduction in episome numbers and emergence of latent integrants. Carcinogenesis, v. 27, n. 11, p. 2341-2353, 2006.

HOGERLINDEN, M. VAN et al. Squamous Cell Carcinomas and Increased Apoptosis in Skin with Inhibited Rel / Nuclear Factor- K B Signaling. Cancer Research, v. 59, p. 3299-3303, 1999.

HSU, D. et al. Interleukin 10 is a potent growth and differentiation factor for activated human B lymphocytes. Proceeding of the National Academy Science U.S.A., v. 89, n. March 1992, p. 1890-1893, 2000.

HUBERT, P. et al. E-cadherin-dependent adhesion of dendritic and Langerhans cells to keratinocytes is defective in cervical human papillomavirus-associated (pre) neoplastic lesions. Journal of Pathology, v. 206, n. April, p. 346-355, 2005.

JEON, S.; LAMBERT, P. F. Integration of human papillomavirus type 16 DNA into the human genome to increase stability of E6 and E7 mRNAs: implications for cervical carcinogenesis. Proceeding of the National Academy Science U.S.A,, v. 92, n. February, p. 1654-1658, 1995.

JOHNSTON, P. A.; GRANDIS, J. R. Stat3 signaling. Molecular Intervention, v. 11, n. 1, p. 18-26, 2011.

JOHUNG, K.; GOODWIN, E. C.; DIMAIO, D. Human papillomavirus E7 repression in cervical carcinoma cells initiates a transcriptional cascade driven by the retinoblastoma family, resulting in senescence. Journal of Virology, v. 81, n. 5, p. 2102-2116, 2007.

JONG, A. DE et al. Human papillomavirus type 16-positive cervical cancer is associated with impaired CD4+ T-cell immunity against early antigens E2 and E6. Cancer Research, v. 64, n. 25, p. 5449-5455, 2004. 
KARIN, M.; GRETEN, F. R. NFKB : Linking inflammation and immunity to cancer development and progression. Nature Reviews Immunology, v. 5, n. September, p. 749-759, 2005.

KLINGELHUTZ, A. J.; FOSTER, S. A.; MCDOUGALL, J. K. Telomerase acttivation by the E6 gene product of human papillomavirus type 16 . Nature, v. 380, p. 79-82, 1996.

KOBAYASHI, A. et al. Evolving immunosuppressive microenvironment during human cervical carcinogenesis. Nature, v. 1, n. 5, 2008.

LARSON, A. W.; LEBIEN, T. W. Cross-linking CD40 on human B cell precursors inhibits or enhances growth depending on the stage of development and the IL costimulus. The Journal of Immunology, v. 40, n. 153, p. 584-594, 1994.

LEE, C. M. et al. Phosphatidylinositol 3-Kinase Inhibition by LY294002 radiosensitizes human cervical cancer cell lines. Clinical Cancer Research, v. 12, p. 250-256, 2006.

LEPIQUE, A. P. et al. HPV16 tumor associated macrophages suppress antitumor T cell responses. Clinical Cancer Research, v. 15, n. 13, p. 4391-4401, 2009.

MA, Y. et al. PIK3CA as an oncogene in cervical cancer. Oncogene, v. 19, n. 27392744, 2000.

MABUCHI, S. et al. Pretreatment leukocytosis is an indicator of poor prognosis in patients with cervical cancer. Gynecologic Oncology, v. 122, n. 1, p. 25-32, 2011.

MARTIN, G. S. Cell signaling and cancer. Cancer Cell, v. 4, n. September, p. 167174, 2003.

MATSUMOTO, Y. et al. Squamous cell carcinoma of the uterine cervix producing granulocyte colony-stimulating factor: a report of 4 cases and a review of the literature. International Journal of Gynecologic Cancer, v. 20, n. 3, p. 417-421, 2010.

MAZIBRADA, J. et al. Interaction between inflammation and angiogenesis during different stages of cervical carcinogenesis. Gynecologic Oncology, v. 108, p. 112120, 2008.

MENGES, C. W. et al. Human papillomavirus type 16 E7 up-regulates AKT activity through the retinoblastoma protein. Cancer Research, v. 66, p. 5555-5559, 2006.

MONACH, P. A. et al. CD4+ and B lymphocytes in transplantation immunity. II. Augmented rejection of tumor allografts by mice lacking B cells. Transplantation, $v$. 55 , n. 6, p. 1356-1361, 1993.

MONTAG, D. T.; LOTZE, M. T. Rapid flow cytometric measurement of cytokineinduced phosphorylation pathways [CIPP] in human peripheral blood leukocytes. Clinical Immunology, v. 121, p. 215-226, 2006. 
MUNN, D. H.; MELLOR, A. L. Indoleamine 2,3-dioxygenase and tumor-induced tolerance. The Journal of Clinical Investigation, v. 117, n. 5, p. 1147-1154, 2007.

MURPHY, T. L. et al. Regulation of interleukin 12 p40 expression through an NF-kB half-site. Molecular and Cell Biology, v. 15, n. 10, p. 5258-5267, 1995.

MURRAY, P. J. The JAK-STAT signaling pathway: input and output integration. The Journal of Immunology, v. 178, p. 2623-2629, 2016.

NISHIZAWA, M.; NAGATA, S. Regulatory elements responsible for inducible expression of the granulocyte colony-stimulating factor gene in macrophages. Molecular and Cellular Biology, v. 10, n. 5, p. 2002-2011, 1990.

PALLANDRE, J. R. et al. Role of STAT3 in CD4+CD25+FOXP3+ regulatory lymphocyte generation: implications in graft-versus-host disease and antitumor immunity. The Journal of Immunology, v. 179, p. 7593-7604, 2007.

PALEFSKY, J. M. et al. Prevalence and risk factors for anal human papillomavirus infection in human immunodeficiency virus (HIV) - positive and high-risk HIVnegative women. The Journal of Infectious Diseases, v. 183, n. February, p. 383391, 2001.

PARKIN, D. M.; BRAY, F. Chapter 2 : The burden of HPV-related cancers. Vaccine, v. 3 , n. 24, p. $11-25,2006$.

PATEL, S.; CHIPLUNKAR, S. Host immune responses to cervical cancer. Gynecologic Cancer, v. 21, p. 54-59, 2009.

PIERSMA, S. J. et al. High number of intraepithelial CD8+ tumor-infiltrating lymphocytes is associated with the absence of lymph node metastases in patients with large early-stage cervical cancer. Cancer Research, v. 67, n. 1, p. 354-362, 2007.

PINHEIRO, C. et al. Monocarboxylate transporters 1 and 4 are associated with CD147 in cervical carcinoma. Disease Markers, v. 26, p. 97-103, 2009.

PORE, N. et al. Akt1 activation can augment hypoxia-inducible factor-1 A expression by increasing protein translation through a mammalian target of rapamycin independent pathway. Molecular Cancer Research, v. 4, n. July, p. 471-480, 2006.

QIN, Z. et al. B cells inhibit induction of T cell-dependent tumor immunity. Nature Medicine, v. 5, n. 6, p. 627-630, 1998.

ROMAGNOLI, G. G. et al. Dendritic cell-drived exosomes may be a tool for cancer immunotherapy by converting tumor cells into immunogenic targets. Frontiers in Immunology, v. 5, p. 1-5, 2015.

ROMANCZUK, H.; HOWLEY, P. M. Disruption of either the El or the E2 regulatory gene of human papillomavirus type 16 increases viral immortalization capacity. Proceeding of the National Academy Science U.S.A,, v. 89, n. April, p. 3159- 
3163, 1992.

RONCO, L. V et al. Human papillomavirus 16 E6 oncoprotein binds to interferon regulatory factor-3 and inhibits its transcriptional activity. Genes and Development, v. 12, p. 2061-2072, 1998.

RUSH, J. S.; HODGKIN, P. D. B cells activated via CD40 and IL-4 undergo a division burst but require continued stimulation to maintain division, survival and differentiation. European Journal of Immunology, v. 31, p. 1150-1159, 2001.

RYAN, A. E. et al. Targeting colon cancer cell NF-kB promotes an anti-tumor M1-like macrophage phenotype and inhibits peritoneal metastasis. Oncogene, v. 34, n. 12, p. 1563-1574, 2015.

SCHEFFNER, M.; WERNESS, B. A.; HUIBREGTSE, J. The E6 oncoprotein encoded by human papillomavirus types 16 and 18 promotes the degradation of p53. Cell, v. 63, n. December, p. 1129-1136, 1990.

SCHLECHT, N. F. et al. Persistent human Papillomavirus infection as a predictor of cervical intraepithelial neoplasia. Journal of American Medical Association, v. 286, n. 24, p. 3106-3114, 2001.

SEITZ, C. S. et al. Alterations in NF-kB function in transgenic epithelial tissue demonstrate a growth inhibitory role for NF-kB. Proceeding of the National Academy Science U.S.A,, v. 95, n. March, p. 2307-2312, 1998.

SEVER, R.; BRUGGE, J. S. Signal transduction in cancer. Cold Spring Harbor Perspectives in Medicine, v. 5, 2015.

SHEHATA, M. F. Rel/Nucelar factor-kappa B apoptosis pathways in human cervical cancer cells. Cancer Cell International, v. 5, n. 10, p. 1-13, 2005.

SHUKLA, S. et al. Functional Regulatory Role of STAT3 in HPV16-mediated cervical carcinogenesis. PLOS One, v. 8, n. 7, 2013.

SILINS, I. et al. Evaluation of antibodies to human papillomavirus as prognostic markers in cervical cancer patients. Gynecologic Oncology, v. 85, p. 333-338, 2002.

SOLOMON, D. et al. The 2001 Bethesda system terminology for reporting results of cervical cytology. Journal of American Medical Association, v. 287, n. 16, p. 2114-2119, 2002.

SON, Y.H. et al. Roles of MAPK and NF-kappaB in interleukin-6 induction by lipopolysaccharide in vascular smooth muscle cells. Journal of Cardiovascular Pharmacology, v. 51, n. 1, p. 71-77, 2008.

STANLEY, M. Immunobiology of HPV and HPV vaccines. Gynecologic Oncology, v. 109, n. 2 SUPPL., p. 15-21, 2008. 
STANLEY, M. HPV - immune response to infection and vaccination. Infectious Agents and Cancer, v. 5, n. 1, p. 19, 2010.

STEGEMAN, $H$. et al. Activation of AKT by hypoxia : a potential target for hypoxic tumors of the head and neck. BMC Cancer, v. 12, p. 2-10, 2012.

STONE, S. C. et al. HPV associated tumor cells control tumor microenvironment and leukocytosis in experimental models. Immunity, Inflammation and Disease, v. 2, n. 2, p. 63-75, 2014a.

STONE, S. C. et al. HPV16-associated tumors control myeloid cell homeostasis in lymphoid organs, generating a suppressor environment for $\mathrm{T}$ cells. Journal of Leukocyte Biology, v. 96, n. October, p. 619-631, 2014b.

TAKEMOTO, S. et al. Expression of activated signal transducer and activator of transcription-3 predicts poor prognosis in cervical squamous-cell carcinoma. British Journal of Cancer, v. 101, n. 6, p. 967-972, 2009.

TAN, T.; COUSSENS, L. M. Humoral immunity, inflammation and cancer. Current Opnion in Immunology, v. 19, p. 209-216, 2007.

TINDLE, R. W. Immune evasion in human papillomavirus-associated cervical cancer. Nature Reviews Cancer v. 2, n. January, p. 59-64, 2002.

TRIMBLE, C. L. et al. Human papillomavirus 16-associated cervical intraepithelial neoplasia in humans excludes CD8 T cells from dysplastic epithelium. The Journal of Immunology, v. 185, p. 7107-7114, 2010.

TRINCHIERI, G. Cancer and inflammation: An old intuition with rapidly evolving new concepts. Annual Review of Immunology, v. 30, p. 677-706, 2012.

UM, S. et al. Abrogation of IRF-1 response by high-risk HPV E7 protein in vivo. Cancer Letters, v. 179, p. 205-212, 2002.

VILLIERS, E. DE et al. Classification of papillomaviruses. Virology, v. 324, p. 17-27, 2004.

VISSER, K. E. DE; KORETS, L. V; COUSSENS, L. M. De novo carcinogenesis promoted by chronic inflammation is B lymphocyte dependent. Cancer Cell, v. 7, n. May, p. 411-423, 2005.

VIVANCO, I.; SAWYERS, C. L. The Phosphatidylinositol 3-Kinase-AKT Pathway in human cancer. Nature Reviews Cancer, v. 2, n. July, p. 489-501, 2002.

WALBOOMERS, J. M. M. Human papillomavirus is a necessary cause of invasive cervical cancer worlwide. Journal of Pathology, v. 189, n. May, p. 12-19, 1999.

WANG, Y. et al. STAT3 activation in response to IL-6 is prolonged by the binding of IL-6 receptor to EGF receptor. Proceeding of the National Academy Science U.S.A., v. 2, n. 22, p. 16975-16980, 2013. 
WEI, L. et al. Interleukin-6 promotes cervical tumor growth by VEGF-dependent angiogenesis via a STAT3 pathway. Oncogene, v. 22, n. 7, p. 1517-1527, 2003.

WELTERS, M. J. P. et al. Detection of human papillomavirus type 18 E6 and E7specific CD4 1 T-helper 1 immunity in relation to health versus disease. International Jounal of Cancer, v. 956, n. September, p. 950-956, 2006.

WILLIAMS, N. L. et al. Adenocarcinoma of the cervix: should we treat it differently? Current Oncology Reports, v. 17, n. 4, p. 17, 2015.

WU, M. Y.; KUO, T. Y.; HO, H. N. Tumor-infiltrating lymphocytes contain a higher proportion of FOXP3+ T lymphocytes in cervical cancer. Journal of the Formosan Medical Association, v. 110, p. 580-586, 2011.

YANG, S. et al. The role of p-STAT3 (ser727) revealed by its association with Ki-67 in cervical intraepithelial neoplasia. Gynecologic Oncology, v. 98, p. 446-452, 2005.

YOSHIMURA, S. et al. Effective antigen presentation by dendritic cells is NF- $\mathrm{K} B$ dependent: coordinate regulation of $\mathrm{MHC}$, co-stimulatory molecules and cytokines. International Immunology, v. 13, n. 5, p. 675-683, 2001.

YU, H.; KORTYLEWSKI, M.; PARDOLL, D. Crosstalk between cancer and immune cells : role of STAT3 in the tumour microenvironment. Nature Reviews Immunology, v. 7, p. 41-51, 2007.

ZHONG, H.; VOLL, R. E.; GHOSH, S. Phosphorylation of NF-kB p65 by PKA Stimulates Transcriptional Activity by Promoting a Novel Bivalent Interaction with the Coactivator CBP / p300. Molecular Cell, v. 1, p. 661-671, 1998.

ZIEGERT, C. et al. A comprehensive analysis of HPV integration loci in anogenital lesions combining transcript and genome-based amplification techniques. Oncogene, v. 22, n. April, p. 3977-3984, 2003.

ZOU, G.; HU, W. LIGHT Regulates CD86 Expression on Dendritic Cells Through NFk B , but not JNK / AP-1 Signal Transduction Pathway. Journal of Cellular Physiology, v. 205, n. February, p. 437-443, 2005. 